\title{
Morinda citrifolia leaf extract ameliorated Leukemia in mice model
}

\begin{abstract}
Leukemia affects over a million people worldwide and disturbs the bone marrow, the spleen and the lymph system. In finding dietary therapy against leukemia the vegetable Morinda citrifolia leaves were investigated and compared with ATRA (alltrans-retinoic acid) in mice. The extract standardised to epicatechin and scopoletin was anti-proliferative against human JURKAT and murine WEHI-3B leukemia cells ( $\mathrm{IC}_{50}$ of 14.5 and $17 \mu \mathrm{g} / \mathrm{ml}$ respectively) in vitro yet was non-toxic to normal peripheral blood mononuclear cells. Leukemia was induced in the BALB/c mice by inoculating WEHI-3B cells subcutaneously. Three days after leukemia development the extract $(100$ and $200 \mathrm{mg} / \mathrm{Kg} \mathrm{BW})$ or ATRA $(5 \mathrm{mg} / \mathrm{kg} \mathrm{BW})$ were fed daily to the mice for four weeks. The extract decreased the leukemic mice peripheral blood immature leukocytes, anemia, total white blood cells; bone marrow blasts cells content and blast cells invasions to the spleen and liver. Electron microscopy and histopathology observations confirmed the extract induced leukemia cells apoptosis similar to ATRA. The extract also mitigated the changes in T-cells and B-cells levels in the leukemic spleen tissues in vivo. The extract dose dependently induced leukemia cells apoptosis both in vitro and in vivo restored all pathological blood, liver and spleen changes in vivo and reinstated the endogenous immune responses to normal healthy levels in vivo.
\end{abstract}

Keywords: morinda leaf, leukemia, in vitro, human Jurkat, mice, murine WEHI-3B, apoptosis
Volume 2 Issue 6 - 2017

\author{
Ahmadi N, ${ }^{1,2,3}$ Rahman HS, ${ }^{1,4}$ Azmi Ibrahim T,' \\ Rosli R, ${ }^{1,3}$ Keong Yeap S,' Mohamed S' \\ 'Universiti Putra Malaysia, Malaysia \\ ${ }^{2}$ Imam Khomeini Hospital, Iran \\ ${ }^{3}$ Department of Medicine and Health Sciences, Universiti Putra \\ Malaysia, Malaysia \\ ${ }^{4}$ University of Sulaimani, Iraq
}

\begin{abstract}
Correspondence: Suhaila Mohamed, Institute of Bioscience, Universiti Putra Malaysia, 43400 Serdang, Selangor, Malaysia, Fax +603-8947-2101, Tel +603-89472168
\end{abstract}

Email mohamed.suhaila@gmail.com

Received: October 24, 2016 | Published: April 17, 2017
Abbreviations: ATRA, all-trans-retinoic acid; NOAEL, no observed-adverse-effect level; ATCC, american type culture collection; TB, tuberculin; EDTA, ethylene diamine tetra acetic acid; WBC, white blood cell; RBC, red blood cell; ALT, alanine transaminase; AST, asparagine transaminase; ALP, alkaline phosphatase; H\&E, hematoxylin \& eosin; IHC, immunohistochemical; SPSS, statistical package for the social sciences; SEM, standard error of the mean; AML, acute myeloid leukemia

\section{Introduction}

Leukemia being a heterogeneous white blood cells neoplastic disorder causes uncontrolled proliferation and blocked differentiation of the hematopoietic cells. Factors that increase leukemia risk include micronutrient deficiency, prior chemotherapy, hereditary syndromes (Down syndrome), ionizing radiation, viruses' infection and smoking. ${ }^{1}$ The existing therapies for leukemia include chemotherapy, radiotherapy, hormonal therapy, immune therapy and bone marrow transplantation. AML chemotherapeutic agents like Daunorubicin, Cytarabine and Idarubicin affect normal cells producing side effects like bleeding, infection and anemia. The present chemotherapies often damage healthy cells and tissues with short to long-term side-effects, but help prolonged the leukemia patients' survival rate. Leukemia affects about 1.6 million people and involves the blood: the bone marrow and the lymph system. About 52,380 cases of leukemia are detected in 2014 , causing 24,090 deaths and affecting more males $(57 \%)$ than females. ${ }^{2}$ The increasing leukemia incidence justifies more research for anti-leukemia alternative and complementary therapies.

Dietary vegetables and herbs help reduce oxidative damage and the related chronic diseases risk. Herbs studied for leukemia therapy include Hibiscus cannabinus, ${ }^{3}$ Vernonia amygdalina $\operatorname{root}^{4}$ Euphorbia formosana, ${ }^{5}$ Allium sativum, ${ }^{6}$ Moringa oleifera ${ }^{7}$ and Typhonium flagelliforme. ${ }^{8}$ Morinda citrifolia (Noni) or 'mengkudu' in Malaysia has been extensively used for its broad therapeutic effects, including various anticancer activities, in both clinical practice and laboratory animal models. ${ }^{9}$ The Morinda citrifolia leaves are often eaten as vegetables after blanching by the locals of South East Asia. The leaves are also traditionally used medicinally to treat wound infections, pain, arthritis, swellings and for general health. The leaves have liver-protective, antioxidant and skin healing effects..$^{10}$ The leaves are scientifically reported to have no acute, sub-acute or sub-chronic oral toxicity. ${ }^{11}$ The oral no observed-adverse-effect level (NOAEL) of M. citrifolia leaves ethanolic extract is $1000 \mathrm{mg} / \mathrm{kg} .{ }^{12}$ This work demonstrates the therapeutic effects of the edible Morinda citrifolia (Mengkudu/Noni) leaf extract for leukemia and the possible modes of action in mice model.

\section{Materials and methods}

\section{Plant materials}

M. citrifolia leaves (Voucher No. SK2322/14, identified by Biodiversity Unit, Institute of Bioscience, University Putra Malaysia, Serdang) were collected from Institute Bioscience, University Putra Malaysia, State of Selangor, Malaysia. The leaves were dried, coarsely ground and soaked overnight in $50 \%$ aqueous ethanol in the leaf: solvent ratio (w/v) of $1: 5(\mathrm{~kg} / \mathrm{l})$, with occasional stirring. The extract was filtered and rotary evaporated to remove all solvents. The yield was $13.6 \%$. The leaf extract is standardized using HPLC (Waters 2996, Milford, MA) analysis for epicatechin (3.4\%) and scopoletin $(2.2 \%) \cdot{ }^{13}$

\section{Cell culture and chemicals}

The murine myelomonocytic leukemia (WEHI-3B) cell line was 
purchased from American Type Culture Collection (ATCC, USA) and maintained in RPMI-1640 (ATCC, USA) medium; supplemented with L-glutamine $(2 \mathrm{mM}), 10 \%$ heat inactivated fetal bovine serum (PAA, Austria) and $1 \%$ of $100 \mu \mathrm{g} / \mathrm{ml}$ penicillin and streptomycin (Biowest, USA). Cells were grown in a humidified incubator at $37^{\circ} \mathrm{C}$ with $5 \%$ $\mathrm{CO}_{2}$. Upon reaching $90 \%$ confluence, the medium was changed and replaced with fresh medium to remove dead cells. The next day, the medium was removed and the cells washed with PBS. The cells were collected immediately by centrifuging at $100 \times \mathrm{g}$ for $10 \mathrm{~min}$ at $4^{\circ} \mathrm{C}$ and washed twice with and dispersed in PBS and finally counted using a haemocytometer. Trypan blue (Sigma Aldrich, USA) staining used to exclude dead cells. Eventually, the cells were suspended in the $300 \mu 1$ PBS. Harvested cells were used within 1 hour of preparation.

The anti-proliferative effects were determined by MTT assay in 96-well plates, seeded at $2 \times 10^{5}$ cells $/ \mathrm{ml}$ and incubated for $24-72$ hours with $M$. citrifolia leaf extract concentration ranging from 1.562$100 \mu \mathrm{M}$. Cell viability were measured by the mitochondrial-dependent conversion of the yellow tetrazolium salt MTT to purple formazan crystals at 570 and $630 \mathrm{~nm}$ (Universal Micro plate reader) (Biotech, Inc, USA) and the $50 \%$ inhibition concentration $\left(\mathrm{IC}_{50}\right)$ determined from the concentration-response curves. Primary Peripheral Blood Mononuclear Cells lymphocyte were separated from whole fresh human blood $(\sim 8 \mathrm{ml})$ using sodium citrate in BD vacutainer ${ }^{\circledR}$ $\left(\mathrm{CPT}^{\mathrm{TM}}\right.$ ) by gently inverting the tube $8-10$ times, centrifuged (Hettich zentrifugen, 32R, Germany) at room temperature in a horizontal rotor (swing-out head) for 20 minutes at $4000 \mathrm{~g}$, plasma aspirated immediately and the whitish lymphocytes layer just under the plasma collected using a Pasteur pipette and transferred into $25 \mathrm{~cm}^{3}$ cell culture flasks containing complete pre-warmed RPMI-1640 culture medium and incubated at $37^{\circ} \mathrm{C}, 5 \% \mathrm{CO}_{2}$. When cells reached near $90 \%$ confluency, total cell density was determined using a hemocytometer and plated in triplicates in a 96-well micro plate.

\section{Leukemia induction-animal model}

The animal research protocol was approved by the University Animal Care and Use Committee (UPM/IACUC/AUP-R033/2013), Serdang, Selangor, Malaysia. Male BALB/C mice (6 weeks old, weighing 19-20g) were from the Faculty of Veterinary Medicine, Universiti Putra Malaysia (UPM). Mice were acclimatised and housed in laminar air-flow cabinets with a 12-h light/12-h dark and fed at libitum with standard chow and water. Leukemia were induced by intraperitoneal injection of WEHI-3B cells $\left(1 \times 10^{6}\right.$ cells/animal $)$ in $300 \mu \mathrm{l}$ PBS using a tuberculin (TB) syringe and $26 \mathrm{G}$ needle on 7 weeks old anesthetised mice. Blood from the tail vein were collected for 3 consecutive days and observed under Wright stain to monitor the leukemia development. The mice were divided into $5(\mathrm{n}=10)$ groups:

i. Untreated normal control healthy mice

ii. Untreated leukemia control

iii. Leukemic mice fed $5 \mathrm{mg} / \mathrm{kg}$ body weight ATRA (all-trans-retinoic acid as positive control)

iv. Leukemic mice fed daily with $100 \mathrm{mg} / \mathrm{kg}$ and

v. $200 \mathrm{mg}$ M. citrifolia leaf extract $/ \mathrm{kg}$ body weight respectively. The treatments were for 4 weeks via gastric intubations.

Blood samples from cardiac puncture on the anaesthetised mice were collected in ethylene diamine tetra acetic acid (EDTA) vacutainers and shaken immediately for automatic and manual haematology analyses, using Automatic Haematology Analyzer (Cell Dyn, 3700, Abbot, USA) for total and differential white blood cell (WBC), red blood cell (RBC) and haemoglobin counts. Some blood were collected in vacutainers, centrifuged (Hettich Zent EBA20, Germany) at $5,000 \mathrm{~g}$ for 5 minutes and the serum collected in eppendorf tubes and stored at $-20^{\circ} \mathrm{C}$, before analysing for alanine transaminase (ALT), Asparagine transaminase (AST), alkaline phosphatase (ALP), total protein, albumin, urea, creatinine, potassium, chloride and bilirubin (Automatic Biochemistry Analyzer, Hitachi 902, Japan). The peripheral blood smears dropped on a glass slide, drawn by a cover slip and left to dry for 20 minutes at room temperature, before Wright's staining and examined with a light microscope (100x, 200x, 400x and 1000x magnifications). Mice were given intraperitoneal injection of ketamine $\mathrm{HCl}(100 \mathrm{mg} / \mathrm{kg})$ and xylazine $(10 \mathrm{mg} / \mathrm{kg})$ before exsanguination and organ examination. The spleen tissues were fixed in formalin and embedded in paraffin. Sections $(5 \mu \mathrm{m})$ were used for TUNEL assays and Lesion Scoring. ${ }^{14}$ The samples were viewed under confocal microscopy using a standard fluorescent filter set to view the green fluorescence at $520 \pm 20 \mathrm{~nm}$ and view red fluorescence of Propidium iodide (PI) at $>620 \mathrm{~nm}$.

\section{Immunohistochemistry (IHC) and lesion scoring of spleen tissue}

Tissues were fixed in $10 \%$ formalin and embedded in paraffin for Hematoxylin and Eosin (H\&E) and Immunohistochemical (IHC) examination. IHC kits (ChemMate ${ }^{\mathrm{TM}}$ DAKO EnVision ${ }^{\mathrm{TM}}$ Detection Kit, Peroxidase/DAB, Rabbit/Mouse) were from Dako, Denmark. Adequate $200 \mu \mathrm{L}$ CD3 primary antibody (T-lymphocyte marker) (Abcam ab5690, UK) or CD19 primary antibody (B-lymphocyte marker) (Bioss bs0079R, USA) reagents was applied to the section and incubated in a humidity chamber at room temperature for $30 \mathrm{~min}$ before rinsing with distilled water and immersing in TBST buffer $(\mathrm{pH}$ 9.0) bath for $3 \mathrm{~min}$.

\section{Statistics}

All data were expressed as means \pm standard error of the mean (SEM). One-way analysis of variance (ANOVA) using Statistical Package for the Social Sciences (SPSS) software version 16.0 for Windows (SPSS Inc., Chicago, Illinois, USA) was used to test for significant differences between treatments $(\mathrm{p}<0.05)$ by the StudentNewman-Keuls multiple range tests.

\section{Results}

\section{Anti-leukemic properties of $M$. citrifolia leaf extract in vitro and in BALB/c mice}

The M. citrifolia leaf extract containing 3.4\% epicatechin and $2.2 \%$ scopoletin (Supplementary data) arrested Jurkat and WEHI$3 \mathrm{~B}$ cells proliferation in vitro with an effective dose $\mathrm{ED} 50$ or $\mathrm{IC}_{50}$ (inhibit $50 \%$ cell growth) of $14.5 \pm 0.1 \mu \mathrm{g} / \mathrm{ml}$ and $17.1 \pm 0.1 \mu \mathrm{g} / \mathrm{ml}$ after 72 hours incubations, respectively. The negative control DMSO showed no inhibition. The extract was not toxic on normal human blood mononuclear cells at up to $100 \mu \mathrm{g} / \mathrm{ml}$ for 72 hours (Figure 1). The leukemia-induced mice showed significant immature myeloid and monocytic cells in circulation, as early as 3 days following intraperitoneal inoculation of WEHI-3B cell line in vivo (Figure 2). These are large with high nucleus to cytoplasm ratio, showing polymorphic nuclei, prominent nucleoli and cytoplasmic blebbing. 


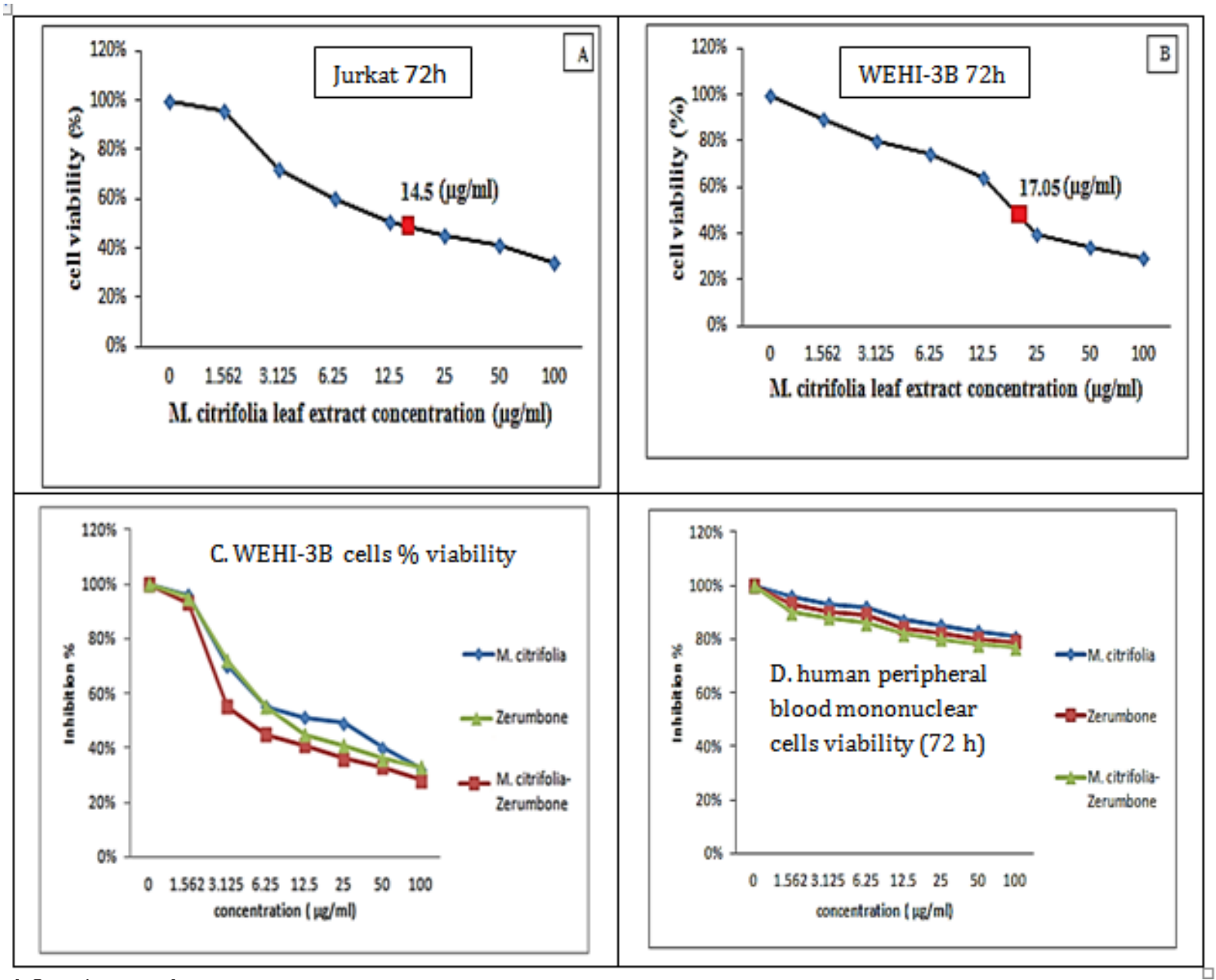

Figure I Growth arrest of

A) Jurkat

B) WEHI-3B 72h

C) WEHI- $3 \mathrm{~B}$ cells \% viability and

D) Human peripheral blood mononuclear cells by M. citrifolia leaf extract, Zerumbone alone or combined Zerumbone+ M. citrifolia leaf extract after $72 \mathrm{~h}$ treatments.

\section{The red blood cells (RBC) and haemoglobin (HGB) counts}

It demonstrated erythropenia and in HGB deficiency levels in untreated leukemia mice compared with healthy mice. Both doses of extract (100 and $200 \mathrm{mg} / \mathrm{kg}$ ) and ATRA treated leukemia mice exhibited normal total and differential white blood cells (WBC) counts, RBC and HGB levels, insignificantly different to healthy mice (Figure 2). The untreated leukemia mice showed significantly different blood profile and expressed severe leukocytosis and monocytosis compared to the healthy mice. Histo-pathological examination of the spleen parenchyma (red and white pulp) indicated that there was a significant $(P<0.05)$ and massive proliferations of pleomorphic neoplastic cells in the untreated leukemic animals which led to the disappearance of the sinusoids. These neoplastic cells were characterized by large irregular nuclei with clumped chromatin, prominent nucleoli and vary considerably in sizes and shapes (Figure 3 ). The spleen tissues of $M$. citrifolia leaf extract or ATRA treated animals demonstrated a significant comparative reduction $(P<0.05)$ in these leukemic cells.

\section{The transmission electron microscopy (TEM)}

It showed the malignant cells in the untreated leukemic mice' spleens were bigger, polymorphic with markedly irregular surfaces and abnormal shaped nuclei, unlike the spleen of normal healthy mice (Figure 4). The M. citrifolia leaf extract and ATRA treated leukemic mice showed cellular apoptotic changes such as peripheral nuclear chromatin condensation (Margination of chromatin), nuclei lobulation and cell membrane blebs (Figure 4), which was different from the controls. Nuclei of apoptotic cells appear brown and granular, while normal nuclei stain blue under staining. The TUNEL Assay of the spleen of healthy and untreated leukemia mice showed no apoptosis (Figures 5), yet apoptosis was significant $(P<0.05)$ in all extract and ATRA treated leukemic mice, evident by the high green fluorescence under the fluorescent microscope. Immunohistochemical assay showed the spleen tissues of the untreated leukemia mice significantly $(P<0.05)$ expressed CD3 (T cell marker) (dark brown colour) in the white pulp and CD19 (B cell marker) in the red pulp. M. citrifolia leaf extract and ATRA treated mice induced a significant $(P<0.05)$ 
reduction in T-cell and B-cell markers in the spleens compared to the untreated leukemia mice. Normal healthy spleens express low levels of T-cell marker or significant B-cell marker (Figure $6 \&$ Figure 7).
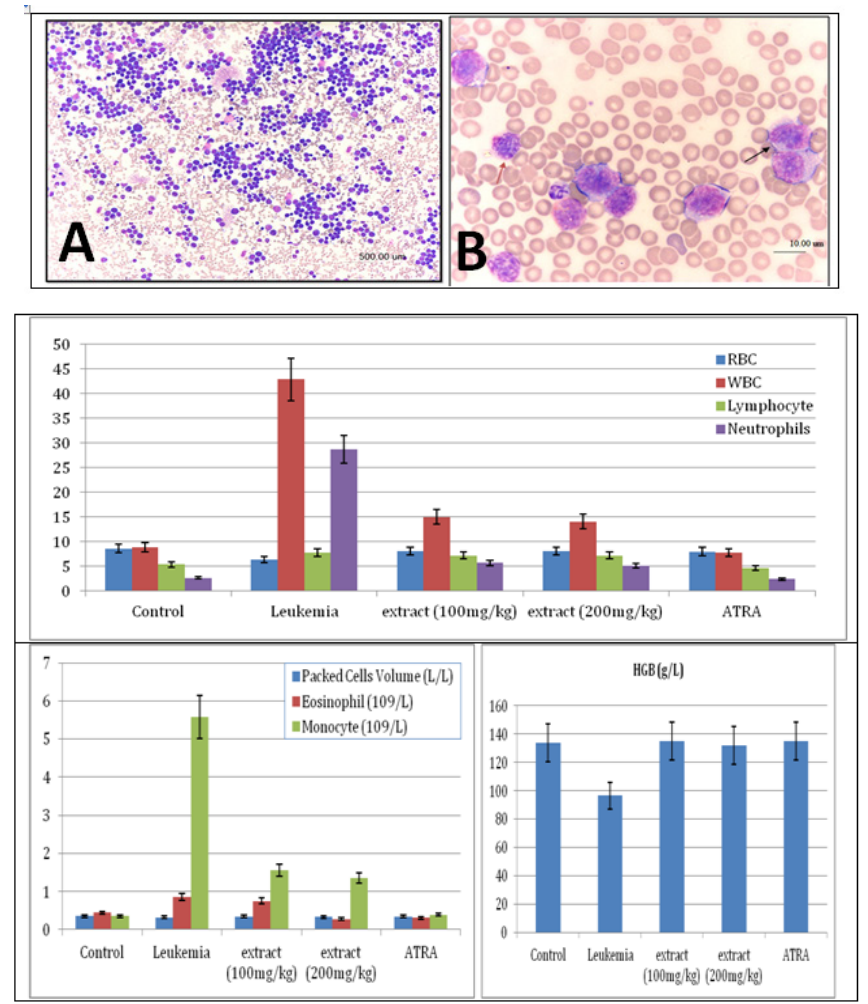

Figure 2 Photomicrograph showing severe leukocytosis in a blood smear of a mouse (leukemia mice), and the mice blood profiles.

A) The peripheral blood smears of a leukemia mice showing leukocytosis. Cells with different sizes and shapes are seen (Wright's stain, $x$ 4) $\left(10^{\%} / \mathrm{L}\right.$ for WBC, $10^{12} / L$ for $R B C$ ).

B) Peripheral blood myeloid (red arrow) and monocytic (black arrow) cells in leukemic BALB/c mice (400 $\times$ Magnification).
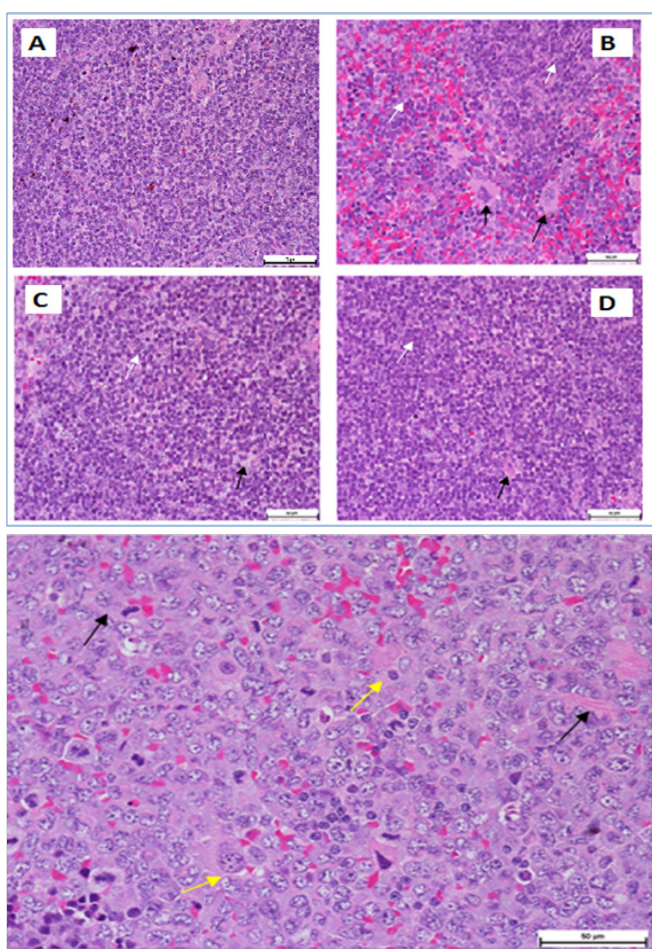

Figure 3 Photomicrograph of a section of a spleen of a leukemia mice mouse. Leukemic cells (black arrows), normal cells (white arrow) (400×Magnification).

A) Normal spleen

B) ATRA-treated represented a significant reduction in leukemic cells in comparison to controls.

C) M. citrifolia leaf extract low dose $(100 \mathrm{mg} / \mathrm{kg})$ demonstrating significant reduction in the number of leukemic cells.

D) M. citrifolia leaf extract high dose $(200 \mathrm{mg} / \mathrm{kg})$ mice demonstrating significant reduction in the number of leukemic cells.

A) Control Leukemia mouse spleen with loss of its normal architecture due to diffused proliferation of the cells.

O: Giant tumour cells formation (yellow arrowheads) and newly formed blood vessels (black arrowheads) (H\&E, x200).

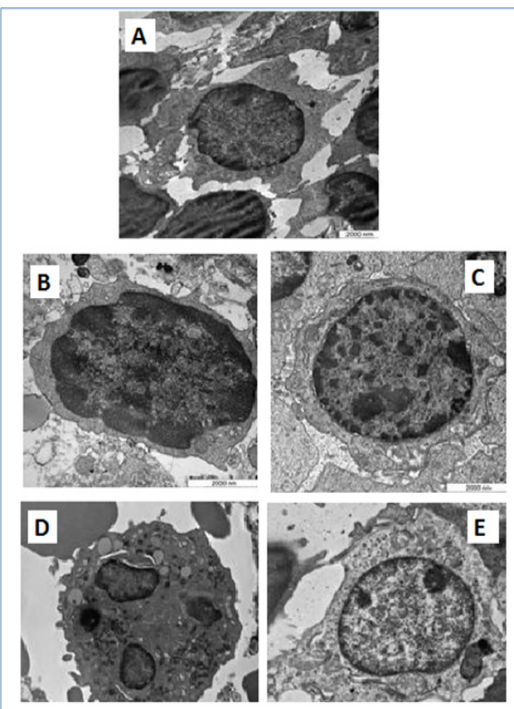

Figure 4 Spleen tissue of leukemic BALB/c mice.

A) Normal spleen

B) Leukemia mice

C) ATRA-treated represented significant changes in leukemic cells in comparison to controls.

D) M. citrifolia leaf extract low dose $(100 \mathrm{mg} / \mathrm{kg})$ mice demonstrating significant changes in leukemic cells.

M. citrifolia leaf extracts high dose $(200 \mathrm{mg} / \mathrm{kg})$ mice demonstrating significant changes in leukemic cells ( $1000 \times$ Magnification). 

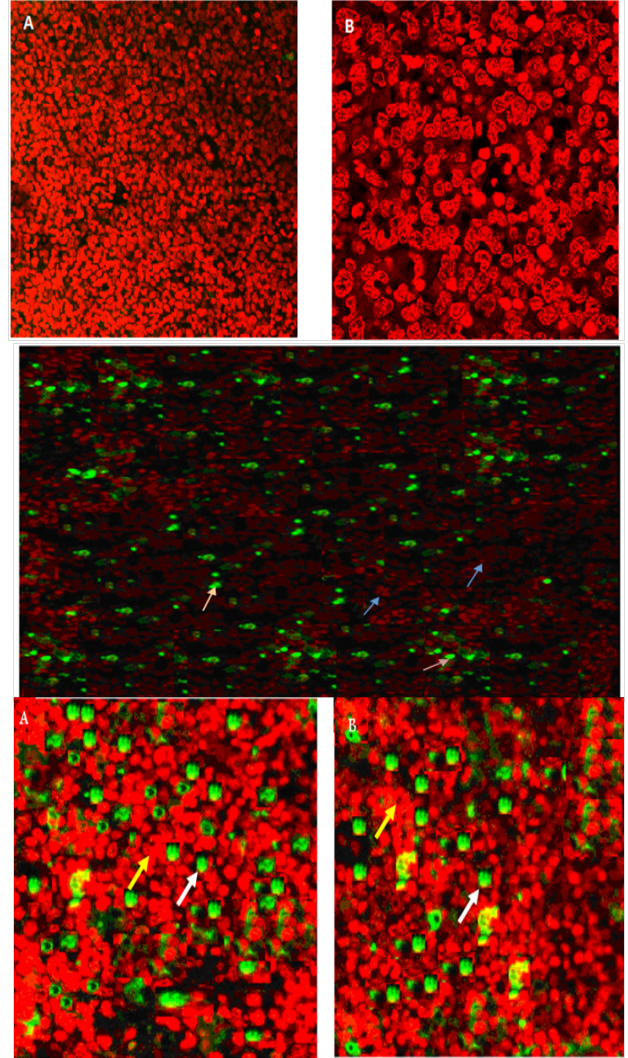

Figure 5 Spleen tissue of BALB/c mice analysed by TUNEL assay.

A) Healthy mice.

B) Leukemic mice.

C) ATRA-treated

D) M. citrifolia leaf extract-treated High dose $(200 \mathrm{mg} / \mathrm{kg})$ showing significant apoptosis.

E) M. citrifolia leaf extract-treated Low dose $(100 \mathrm{mg} / \mathrm{kg})$ showing significant apoptosis.

A \& B: Mostly non-apoptotic cells and few apoptotic cells $C$ shows significant apoptosis (Non apoptotic cells (blue arrow), apoptotic cells (pink arrow) (400×Magnification)

D \& E: Non apoptotic cells (yellow arrow), apoptotic cells (White arrow) (400 $\times$ Magnification).

Note: Green cells are TUNEL+.
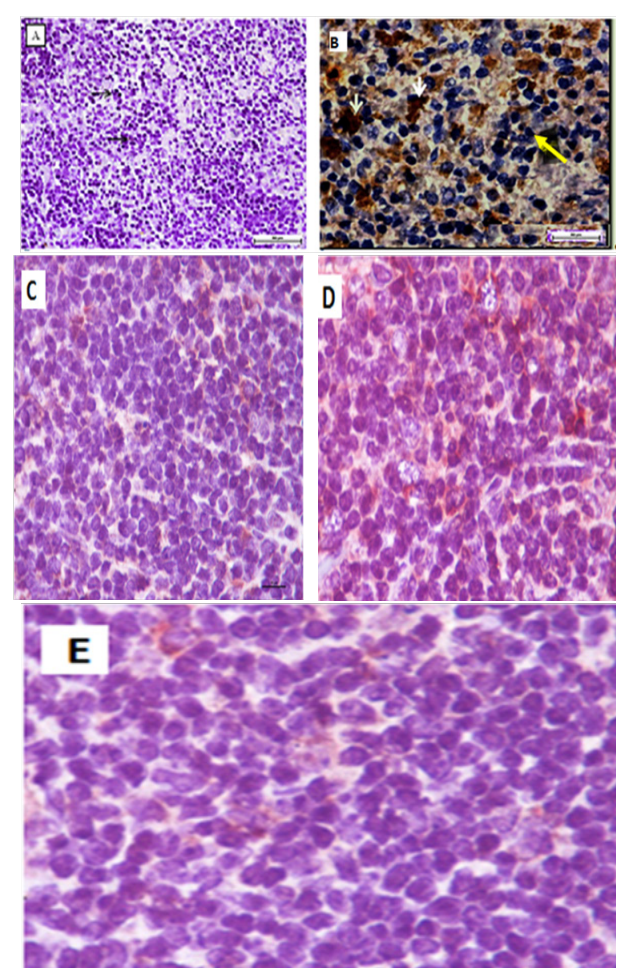

Figure 6 Immunohistochemical staining of BALB/c mice spleen tissues with CD3 T.

A) Healthy shows negative expression of CD3 T cell marker.

B) Neoplastic cells of leukemia control mice showing significant and strong expression of CD3 T-cell marker. Negative cells (yellow arrow) positive cells (white arrow) (400×Magnification).

C) ATRA-treated.

D) M. citrifolia leaf extract low dose mice.

E) M. citrifolia leaf extract high dose mice. All mice showing significant reduction in T-cell marker. Negative cells (black arrow), positive cells (red arrow) (400×Magnification).

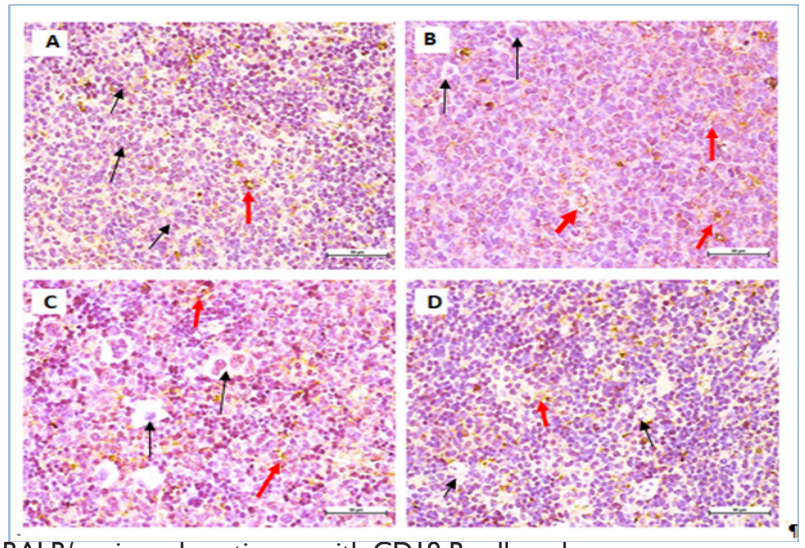

Figure 7 Immunohistochemical staining of BALB/c mice spleen tissues with CDI9 B cell marker.
A) Leukemia mice.
B) ATRA-treated.
C) M. citrifolia leaf extract low dose $(100 \mathrm{mg} / \mathrm{kg})$ mice.
D) M. citrifolia leaf extract high dose $(200 \mathrm{mg} / \mathrm{kg})$ mice.

All mice showing non-significant expression of CDI9 B-cell marker. Negative cells (black arrow), positive cells (red arrow) (400×Magnification). 


\section{Discussion}

Leukemia induction in BALB/c mice by i.p. injection of WEHI$3 \mathrm{~B}$ cells is an recognised methodology for studying new potential anti-leukemia agents. ${ }^{15}$ The aggressive malignant acute myeloid leukemia (AML) consists of fast growing abnormal white blood cells (WBCs) and this mice model has the characteristic elevated peripheral immature monocytes and granulocytes with enlarged and infiltrated abnormal spleens. The M. citrifolia leaf extract showed comparable therapeutic effects to ATRA in decreasing these peripheral immature leukocytes, total white blood cell, bone marrow blasts cells content and blast cells infiltration into the organs of the pathological leukemic mice. The positive control ATRA is a physiologically active metabolite of vitamin A and has no effect on body weight in leukemic animals. Retinoids are potent agents for controlling cellular differentiation and proliferation and often used for hemopoietic malignancies therapy in vivo. ${ }^{16}$ Other clinical signs of leukemia, including splenomegaly and hepatomegaly in the control leukemia mice, ${ }^{17}$ were mitigated by the extract treatment, evidenced by the significant reduction in the spleens and livers towards the sizes and weights of normal mice. The aggressive WEHI-3B leukemia cells had invaded the blood forming organs including the spleen and liver of the leukemia-induced mice. Non blood forming organs like the kidneys did not show any changes.

The ultra-structure of the pleomorphic neoplastic cells reflects the degree of leukemia malignancy. The cells had large and irregular prominent nucleolus. The cytoplasmic nuclear ratios were few to moderate with occasional cytoplasmic organelles, a few spherical mitochondria, rough endoplasmic reticulum dispersed within the cytoplasm and lysosomes. The nuclei showed marginated heterochromatin appearing as dense line along the nuclear envelope, with abnormally distributed ribosomes and the cell membranes were irregular with atypical gap junctions. The cells' nuclei had heterochromatin, large nucleolus, large and numerous mitochondria, rough endoplasmic reticulum, ribosomes and double membrane nuclear envelop. The M. citrifolia leaf extract or ATRA treatment induced apoptotic cell death in the neoplastic spleen cells. The apoptotic cells were characterized by markedly irregular cell surfaces, cell membrane blebbing and bizarre shaped nuclei under the TEM and characterised by peripheral nuclear chromatin condensation (margination of chromatin) and nuclei lobulation. Leukemia mice also showed decreased RBC, HGB and packed cell volume (PCV) which suggests anaemia conditions, due to the cancer cells effect on the bone marrow that disturbed the normal red blood cell production (haematopoiesis) and changed micro environmental cytokines levels. The slightly increased eosinophil levels were also linked to bone marrow cancer infiltration. ${ }^{18}$ The severe abnormalities, including peripheral leukocytosis and monocytosis characteristic of leukemia were mitigated by the extract and ATRA treatments.

Leukemic cells apoptotic induction by $M$. citrifolia leaf was evidenced by the TUNEL (Terminal Deoxynucleotidyl Transferase dUTP Nick End Labelling) assay and ultra-structural examinations. Histo-pathological variations ranged from minimal changes to scanty small neoplastic cell nests present in the sinusoid of the treated leukemic mice spleens. ${ }^{19}$ The Immunohistochemical stain showed the leukemia mice spleen had abundant cell surface biomarkers expression for leukocytes, particular T cell marker (CD3) and B cell marker (CD19), (brown stained cells) which indicate the endogenous immune response towards the leukemia invasion. They were relatively absent in the normal healthy mice spleens and treatments with $M$. citrifolia leaf extract, decreased the CD3 and CD19 markers expressions significantly $(\mathrm{p}<0.05)$ in the leukemic mice spleen, indicating mitigation of the cancer invasion and restoration of the immune responses back to regular healthy conditions. The extract apparently helped inhibit the fast-dividing immature blast leukocytes proliferation.

M. citrifolia contains anthraquinones that are anti-angiogenic and epicatechin, an antioxidant flavonoid that prevents the cancer mitosis and favours cell death. Terpenoids (beta-carotene) boost the thymus gland and immune system to help distribute $\mathrm{T}$ cells that destroy invading cancers. Proxeronine, when combined in the body with proxeronine, forms xeronine which is able to modify the molecular structure of abnormal proteins (such as an enzyme receptor, or signal transducer) by interacting with it and help fold it into its proper conformations, to restore its functions. Xeronine helps to rebuild the damaged cells. ${ }^{20}$ Six M. citrifolia compounds (anthraquinones, epigallocatechin gallate, monoterpenes, terpenoid compounds and proxeronine) are cancer preventive. ${ }^{21}$ Damnacanthal, isolated from this herb can induce normal phenotypes in ras-transformed (cancer) cells. $^{22}$ HPLC analysis shows the leaf extract is rich in epicatechin $(3.4 \%)$ and scopoletin $(2.2 \%) .{ }^{13}$ Both epicatechin and scopoletin in isolation caused leukemia cells apoptosis..$^{19,23}$ Thus the Morinda citrifolia leaf potent anti-leukemic effects may be partly associated with the additive or synergistic effects of epicatechin, scopoletin and possibly other bioactive components.

\section{Acknowledgements}

The authors are grateful to the Herbal development office for the research grant and the staffs of Universiti Putra Malaysia for their kind help and support, especially UPM-MAKNA-Cancer Research Laboratory, Institute of Bioscience for the laboratory facilities and technical assistance (Malaysian Ministry of Agriculture, HDD NRGS grant No NH0513S009).

\section{Conflict of interest}

The author declares no conflict of interest.

\section{References}

1. Eden T. Aetiology of childhood leukaemia. Cancer Treat Rev. 2010;36(4):286-297.

2. Cancer Facts and Figures. Atlanta, Georgia: American Cancer Society; 2014.

3. Foo JB, Yazan LS, Chan KW, et al. Kenaf seed oil from supercritical carbon dioxide fluid extraction induced G1 phase cell cycle arrest and apoptosis in leukaemia cells. African J Biotechnol. 2011;10(27):5389-5397.

4. Khalafalla MMM, Abdellatef E, Daffalla HM, et al. Anti-leukemia activity from root cultures of Vernonia amygdalina. J Med Plants Res. 2009;3(8):556-562.

5. Hsieh YJ, Chang CJ, Wan CF, et al. Euphorbia formosana root extract induces apoptosis by caspase-dependent cell death via Fas and mitochondrial pathway in THP-1 human leukemic cells. Molecules. 2013;18(2):1949-1962.

6. Hassan HT. Ajoene (natural garlic compound): a new anti-leukaemia agent for AML therapy. Leuk Res. 2004;28(7):667-671.

7. Eltayb ANA, Hussein MD. Anti proliferative action of Moringa oleiferaLam. Root extracts in acute myeloid leukemia (AML) cell line. $J$ Exp Sci. 2010;1:27-28.

8. Mohan S, Abdul AB, Abdelwahab SI, et al. Typhonium flagelliforme induces apoptosis in CEMss cells via activation of caspase-9, PARP cleavage and cytochrome c release: its activation coupled with G0/G1 phase cell cycle arrest. J Ethnopharmacol. 2010;131(3):592-600. 
9. Monthanapisut TKSP, Saensuk. Anti-cancer effect of Morinda citrifolia (Noni) on oral cancer cells. Prelim progr annu sci meet $19^{\text {th }}$ Int assoc dent res asia div $13^{\text {th }}$ Southeast Asia assoc dent educ; Malaysia; 2004. p. 3-6.

10. Nayak BS, Sandiford S, Maxwell A. Evaluation of the Wound-healing Activity of Ethanolic Extract of Morinda citrifolia L Leaf. Evid Based Complement Alternat Med. 2009;6(3):351-356.

11. West B, Tani H, Palu A, et al. Safety tests and anti nutrient analyses of noni (Morinda citrifolia L) leaf. J Sci Food Agric. 2007;87(14):25832588.

12. Lagarto A, Bueno V, Merino N, et al. Safety evaluation of Morinda citrifolia (noni) leaves extract: assessment of genotoxicity, oral short term and subchronic toxicity. J Intercult Ethnopharmacol. 2013;2(1):15-22.

13. Lim SL, Goh YM, Noordin MM, et al. Morinda citrifolia edible leaf extract enhanced immune response against lung cancer. Food Funct. 2016;7(2):741-751.

14. Santana P, Peña LA, Friedman HS, et al. Acid sphingomyelinase-deficient human lymphoblasts and mice are defective in radiation-induced apoptosis. Cell. 1996;86(2):189-199.

15. Tsou MF, Tien N, Lu CC, et al. Phenethyl isothiocyanate promotes immune responses in normal BALB/c mice, inhibits murine leukemia WEHI-3 cells and stimulates immunomodulations in vivo. Environ Toxicol. 2013;28(3):127-136.
16. Kiningham KK, Cardozo ZA, Cook C, et al. All-trans-retinoic acid induces manganese superoxide dismutase in human neuroblastoma through NF-kappaB. Free Radic Biol Med. 2008;44(8):1610-1616.

17. Lin JP, Yang JS, Lu CC, et al. Rutin inhibits the proliferation of murine leukemia WEHI-3 cells in vivo and promotes immune response in vivo. Leuk Res. 2009;33(6):823-828.

18. Bokoch GM. Chemoattractant signaling and leukocyte activation. Blood. 1995;86(5):1649-1660.

19. Papiez MA, Baran J, Straková BK, et al. Antileukemic action of (-)-epicatechin in the spleen of rats with acute myeloid leukemia. Food Chem Toxicol. 2010;48(12):3391-3397.

20. Wang MY, West BJ, Jensen CJ, et al. Morinda citrifolia (Noni): a literature review and recent advances in Noni research. Acta Pharmacol Sin. 2002;23(12):1127-1141.

21. Wang MY, Su C. Cancer preventive effect of Morinda citrifolia (Noni). Ann N Y Acad Sci. 2001;952:161-168.

22. Aziz MYA, Omar AR, Subramani T, et al. Damnacanthal is a potent inducer of apoptosis with anticancer activity by stimulating p53 and p21 genes in MCF-7 breast cancer cells. Oncol Lett. 2014;7(5):1479-1484.

23. Kim EK, Kwon KB, Shin BC, et al. Scopoletin induces apoptosis in human promyeloleukemic cells, accompanied by activations of nuclear factor $\kappa \mathrm{B}$ and caspase-3. Life Sci. 2005;77(7):824-836. 